\title{
ONLINE COACH DEVELOPMENT AND CERTIFICATION PROGRAMS IN SPORTS: ARE THEY POSSIBLE?
}

\author{
Konstantinos G. Papageorgiou \\ Department of Informatics, Ionian University, Corfu, Greece \\ Address for coprespondence: \\ Konstantinos G. Papageorgiou \\ Department of Informatics, Ionian University, Corfu, Greece \\ 7 Tsirigoni Square Corfu, 49100 \\ E-mail: cconstantinoss@gmail.com
}

\begin{abstract}
Ahstract Anticipating the inevitable shift of coach education and Coach Certification Programs (CCP) to distance-learning platforms in the imminent future, I have attempted to identify obstacles that we are likely to face. After explaining the rationale and the potential benefits of such courses, I have identified technique as the most difficult component to both teach and evaluate. A specific viewpoint regarding technique is briefly discussed and several related guidelines are provided to assist in both teaching (coach education) and evaluating technique (CCP) within the context of distance education.
\end{abstract}

Key WOrls online learning, distance education, tennis, distal method, technique

\section{Introduction}

The current coronavirus (COVID-19) pandemic has hit hard and it is expected that there will be a postCOVID-19 era. The quarantine-measures, lockdowns, and "social distancing" in many countries will have a lasting effect on our psychology. The impact on the economy, public health, and education will be no less significant; global economic recession seems inevitable; stress, reduced physical activity and lockdowns make up an explosive cocktail contributing to domestic violence and even murders, suicides, increased mortality rates from cardiovascular diseases. In light of these changes, online learning has become the new normal, and will be our focus here.

As online learning is definitely on the rise (Zheng, Lin, Kwon, 2020), we must ask: can we provide online certification programs to coaches? The author is currently working towards that goal; a goal that seems unavoidable, "because it crossed our minds". Let me explain myself: in Dürrenmatt's "Die Physiker", at some point, the "crazy scientist" of the play, Fräulein Doktor Mathilde von Zahnd, expresses a big truth about whatever is thinkable "weil es Denktbar ist". ' Because something is thinkable, we have a moral responsibility towards its potential to become

1 "Er versuchte zu verschweigen, was nicht verschwiegen werden konnte. Denn was inm offenbart worden war, ist kein Geheimnis. Weil es denkbar ist", meaning: "He tried to conceal what could not be kept concealed. Because what was revealed to him 
a reality. If something is thinkable, Fräulein Doktor Mathilde von Zahnd argues, it is the same as if it were already real. In light of that, it seems unavoidable that online certification programs for sports will become a reality in an era that "the impossible becomes a reality". The COVID-19 pandemic seems to have simply accelerated the inevitable (in my opinion there will be a demand for such programs) and so in this article I will examine how such a thing might be possible, despite the obvious restrictions.

Firstly, I will examine the differences between certification programs and coach development. The Coaching Association of Canada (CAC) distinguishes three levels on their webpage (Lifelong Learning Definitions, 10.04.2020):

- in training: a coach has completed some of the required training for a context,

- trained: a coach has completed all required training for a context,

- certified: a coach has completed all evaluation requirements for a context.

Being trained or "developed" is to be educated, while being certified means that one has been evaluated based on a curriculum and therefore able to demonstrate mastery in areas such as "program design, practice planning, performance analysis, program management, ethical coaching, support to participants during training, and support to participants in competition" (McQuade, 2020, p. 200). CCP are not there to develop coaches but to verify the success of a coaching development program - hence education and certification organizations are different entities. So, while coach development provides coaching skills, coach certification provides social credibility. In practice, "coach development" and "CCP" are almost interchangeable.

\section{Certification standards and requirements}

The many problems of coach certification date back to the 50's and are relevant even now (Schweitzer, 1989). Related issues are:

1. The supply-demand conflict.

2. Difference in requirements.

3. Bridging the gap between theory and practice.

4. Expertise models.

5. Social stereotypes.

The ebb and flow of certification requirements are driven by this supply and demand conflict. A lack of available trainers loosens even State standards; for example, Greek sports federations may provide fast-paced developmentcertification programs in specific sports - usually when there is a lack of trainers. In the year 2000, when the standard for a state license was a BA (Hons) in sports science, the federation was keen to establish seminars that provided a state license in two weeks and again in 2018, where the duration was a month. However, this is neither a Greek phenomenon nor a new one (Sabock, 1981).

This problem is further magnified by differing requirements, not only among distant parts of the world, but also adjacent states and even within states over short periods of time. An official certification from the same organization one year later may become unofficial (as is the case with the special-needs education seminars in Greece). Certification business around the globe are not always consistent - at least in tennis.

Do universities contribute to the structure of such programs? As was already identified by C. Schweitzer (1989), scholarly knowledge must be reflected in the certification program structure. However, an additional obstacle 
is the gap between educators and "scientists" (Cain, 2015; Mclntyre, 2005) - it is not just about knowledge, but also about what is considered "relevant" to the coaches and their every-day practice sessions. That issue is also due to the social pressure driven by stereotypes: a successful athlete must be a successful coach. Especially in tennis, where the playing skills of the coach are considered essential, and expertise in receiving and providing training are considered one and the same. Elsewhere, I support that this is also due to the wrong type of expertise that coaches have (there is not just one type of expertise!). There is the classic dichotomy between the contributory and the interactional expert (Collins, Evans, 2007). A good athlete (a contributory motor expert) is just an interactional expert in sports science. This is a distinction we must not forget when choosing or educating any kind of expert. Besides that, I have introduced a new demarcation criterion, that of the methodological scope of expertise. This leads to contributory expert generalists in sports (the Secondary Synthetic Coach Model) that have a broad understanding (surveillance is the technical term) of the entire evolution of athletes (Papageorgiou, 2020a). Certifications should be developed in such a way that this kind of difference is taken into account and adequately tested (cf. the Turing test-like procedures in H.M. Collins, Evans, 2002).

\section{Online courses \& Coaching Certification Progrpams (CCP's)}

CCP's offer a variety of benefits to coaches:

- improved game strategy and technical efficacy of certified coaches (Kai-Sim Lee, Malete, Feltz, 2002),

- increased confidence level of CCP participants (Campbell, Sullivan, 2005),

- effective theoretical and practical knowledge acquisition (Haslam, 1990),

- improved performance of athletes when trained by certified coaches (Misener, Danylchuk, 2009).

For coaches these four characteristics are the most valuable: (a) the structure of the program must have a logical, sequential and comfortable format; (b) pedagogical knowledge should be taught to the participants and modeled by the program facilitators; (c) knowledgeable program facilitators providing relevant content knowledge are essential; and (d) an introduction to, and integration of, pertinent research in sport pedagogy and subject matter content must be apparent (Mccullick, Belcher, Schempp, 2005).

All in all, a CCP should be:

- empowering for its participants,

- effective via the tools it provides,

- holistic by addressing all the developmental parameters (physical, mental),

- balanced as far as theory and practice are concerned,

- enriched providing many approaches to address each issue.

Note: it is evident that CCP and coach development programs are not really separated in both literature and practice. Usually, an online course also offers quizzes, assignments, or some form of additional final examination leading to certification. This implicit convention is also used here (while trying to also refer to their differences).

In principle, the aforementioned characteristics are achievable through an online course. There is a great scarcity of online coach development programs and only a few references, e.g. the use of videos for coachingskills development of university students (Born, Nguyen, Grambow, Meffert, Vogt, 2018). Other fields have greatly benefited from such online courses. Health sciences offer a good reference point for sports since they too combine theory and practice. Nurses and other health professionals may improve their clinical practice using such online courses (Brooks et al., 2020; Ortega-Morán et al., 2020). Platforms, such as Edx, are full of certification courses 
for both students and the general public. While certification courses for sports are not yet widespread, courses for biomechanics, sports statistical analysis, anatomy, physiology and the like already exist on numerous platforms.

Potential benefits of the era of online CCP include:

- better access to knowledge in distant parts of the world,

- better communication among coaches located in distant parts of the world,

- reduced cost of acquiring knowledge and skills,

- development of higher coaching standards, provided quality prevails over quantity,

- increased physical literacy.

Whether a platform offers just coach development, coach certification, or both, the central question remains: What cannot these online platforms provide? Playing skills seem to be the one thing online courses may have a difficulty in providing to coaches - or, worse still, to evaluate and certify.

\section{Developing and evaluating sports skills}

Recently I have launched an online coach development program for tennis called the Distal Method Coach Development (DMCD - Papageorgiou, 2020a). While much of its curriculum can be conveyed online, what happens with the biomechanical model, i.e. its presentation and the evaluation of the coaches' understanding of it? Not their theoretical understanding, but their ability to perform and teach the skills.

For years people have been learning motor skills by watching videotapes (for example, N. Bollettieri's "[tennis] Stroke Instruction Series" from the "90s or the even older videotapes of M. Saito's instructional Aikido videotapes). More recently, YouTube videos with technical explanations and learning tips have also become popular. Slow motion videos of professional players, views from different angles, diagrams, players' comparisons etc. all are being utilized to "teach" skills and technique visually. No formal evaluation of these methods has taken place, even though the literature regarding various forms of feedback and video-feedback is huge (however, video-feedback is used on-site, not as a means of distance learning).

To approach the problem of conveying and evaluating skills in distance learning, I will break the question into three components.

\section{How do we leapn a technique?}

Everything starts at the neurophysiological level of our monkey neurons (Rizzolatti, Fadiga, Gallese, Fogassi, 1996; Terrace, 2001). Humans have an amazing inherent ability to copy what we see. This is why I advise former players who are poor coaches to stop giving directions to children and instead show them the moves. Typically, what they do is different from what they say, usually because they simply do not really know what it is that they themselves do (and usually what they do is less ugly than what they say). At the level of instruction, one may use reference points or "snapshots" of static positions that are simple and universal. For example, the "readiness position", where the arm is fully extended backwards, the elbow is fully supinated and the wrist fully extended. Such reference points can be checked by the player either through vision, proprioception (internal bodily feeling) or both.

For our next step we must differentiate between sensation, feeling, technical model (technique), technical form - our goal for coach online development - and technical style - the athlete's long-term goal (see also Papageorgiou, 2020b). A quintuple distinction not made in the relevant literature:

- sensation: the universal haptic feedback, 
- feeling: the personal psychosomatic imprint of a specific set of body sensations,

- technique: the universal abstract technical model,

- form: the adaptation of the technique to human bodies,

- style: the long-term unique, personal, and effortless adaptation of form to the specifics of our own bodies.

Note: it is also valid for our model to include emotions as the next step after feelings. However, emotions need extended practice (at another level also), whereas feeling is quicker and can lead us directly to the form.

The form is preceded by the feeling and feelings are preceded by sensation. The external study of form as kinesiology does not concern the players themselves. For the players what matters is what they sense, what they feel and what they feel about it. Every form has a different sensation on our body and also feels different - many martial artists use the word "taste" to describe this - i.e. every form has a different taste. This is another reason why we should consciously practice our skill to observe our body. In any case, the coach tries to teach the athlete, to train them (to addict them in a sense) to a certain body sensation which, of course, for the literature translates into a biomechanical model. The body, however, is not programmable with biomechanical data: it needs kinesthetic integration, a process that creates specific feelings. Feelings themselves, either separately or in combination with each other, also produce, or bring to the surface, emotions. For this reason, the element of aesthetic experience, art, is inherent in motor skills-training. This is the reason why e.g. theatrical pedagogy is so important in the development of the athletes.

Now, if we include tactics, a certain learning hierarchy emerges: feeling is first, followed by form (second), followed by tactics (third). The reverse hierarchy applies to competition: there, tactics dictate the technique to be used which we express as a certain form by consciously accessing the respecting feeling through a connection we have been building for years during practice sessions. In competition, if form becomes a priority over tactics - due for example to injury or lack of skill - then we necessarily have a limitation of our possible tactical choices.

\section{How do we convey the procedural knowledge of a skill in distance learning?}

We should understand firstly what we want to do. Our target group is coaches, not players. Therefore, we do not want to develop contributory motor experts (competitive players) but interactional motor experts (coaches capable of demonstrating proper form); we do not want to develop interactional expert coaches (ex-players who know a thing or two about training), but contributory expert coaches (specialists or generalists). Our target group should not expect to learn how to win tournaments, but how to acquire the basic technical form and demonstrate it to learners in non-competitive conditions. We want to develop minimally competent tennis coaches in the DMCD technical model, which means that they are already at least minimally competent as players.

In order to effectively convey the procedural part of the form we should:

1. Use videos where the form is demonstrated from various angles.

2. Always refer to the sense of the form.

3. Provide reference points.

Taken together, these three points should solve the issue of communicating procedural knowledge in distance learning. Another parameter that is important for the success of both online teaching techniques and the other parts of the course is the existence of a community. Online learning built around an active and engaged community is more likely to achieve its goals (Jia et al., 2019). 


\section{How do we evaluate the procedural knowledge of coaches in CCP?}

There are many instances where athletes (motor experts) are formally evaluated at a distance. Martial artists performing a Kata, dancers, pilots. Obviously, informal evaluations are everywhere in sports: TV and radio commentators discuss technique and tactics, YouTube channels analyze and evaluate strokes, websites host numerous presentations of athletes' technique etc.

To automate such a procedure, one might look to Artificial Intelligence programs (expert systems) detecting movement in real-time. Technically this is possible but the cost, for the time being, is too high. For now, the simplest way to do such an evaluation is through a webinar or video-call - where not only can technique be evaluated, but micro-corrections can be fed back, too.

It seems that certifying coaches should include at least one such session. Mobile phones have made it possible to live-stream directly from a tennis court and I suggest online CCP should include at least one webinar session. I am against fully automated certification procedures.

If the aforementioned guidelines are followed, both online coach development and online CCP may be successfully implemented.

\section{Conclusions}

The inevitable shift to online training and certification in the next few years should find us open and ready to embrace its many potential benefits. The potential obstacle identified was the communication and the evaluation of the technical part through an online course. The solutions identified were:

1. Use of videos.

2. Sense-anchors.

3. Reference points.

4. Live webinars (evaluation).

Limitations: we have not touched the issue of the structure of courses or the structure of the platform that best serves such an online learning program. We have not referred to the need for periodic re-evaluations.

Future directions: what about the future? As far as the courses are concerned, we should expect to eventually see augmented reality training systems integrating expert systems. Technical and tactical learning and evaluation will become automated. So, what about the broader picture? Unfortunately, this may not be the last lockdown we experience. Experts in infectious disease have long warned that we might face such a pandemic and warn that we might face one again. For us, the best practice is to be prepared.

\section{References}

Born, P., Nguyen, N.P., Grambow, R., Meffert, D., Vogt, T. (2018). Embedding tennis-specific teaching videos into long-term educational concepts to improve movement learning and technique performances. Journal of Physical Education and Sport, 18 (1), $255-261$. DOI: 10.7752/jpes.2018.01034.

Brooks, A.J., Maizes, V., Billimek, J., Blair, J., Chen, M.-K., Goldblatt, E., Lebensohn, P. (2020). Professional development in integrative health through an interprofessional online course in clinical settings. EXPLORE. DOI: 10.1016/j.explore.2020.02.014. 
Cain, T. (2015). Teachers' engagement with published research: addressing the knowledge problem. Curriculum Journal, 26 (3), 488509. DOI: 10.1080/09585176.2015.1020820.

Campbell, T., Sullivan, P. (2005). The Effect of a Standardized Coaching Education Program on the Efficacy of Novice Coaches. AVANTE, 11 (1), 38-45.

Collins, H., Evans, R. (2007). Rethinking expertise. Chicago: The University of Chicago Press.

Collins, H.M., Evans, R. (2002). The Third Wave of Science Studies: Studies of Expertise and Experience. Social Studies of Science 32/2, 2 (2), 235-296.

Haslam, I.R. (1990). Expert assessment of the national coaching certification program (NCCP) theory component. Canadian Journal of Sport Sciences = Journal Canadien Des Sciences Du Sport, 15 (3), 201-212.

Jia, M., Gong, D., Luo, J., Zhao, J., Zheng, J., Li, K. (2019). Who can benefit more from massive open online courses? A prospective cohort study. Nurse Education Today, 76, 96-102. DOI: 10.1016/j.nedt.2019.02.004.

Kai-Sim, L., Malete, L., Feltz, D.L. (2002). The Strength of Coaching Efficacy Between Certified and Noncertified Singapore Coaches. International Journal of Applied Sports Sciences, 14 (1), 55-67.

Lifelong Learning Definitions. Retrieved from: https://coach.ca/lifelong-learning-definitions (10.04.2020).

Mccullick, B.A., Belcher, D., Schempp, P.G. (2005). What works in coaching and sport instructor certification programs? The participants' view. Physical Education \& Sport Pedagogy, 10 (2), 121-137.

McIntyre, D. (2005). Bridging the gap between researchand practice. Cambridge Journal of Education. DOI: 10.1080/03057640500319065.

McQuade, S. (2020). Current Models of Coach Education, Training, and Certification. In: K. Dieffenbach, M. Thompson (eds), Coach education essentials (p. 448). Human Kinetics.

Misener, K.E., Danylchuk, K.E. (2009). Coaches' Perceptions of Canada's National Coaching Certification Program (NCCP): Awareness and Value. International Journal of Sports Science \& Coaching, 4 (2), 233-243.

Ortega-Morán, J.-F., Pagador, B., Maestre-Antequera, J., Arco, A., Monteiro, F., Sánchez-Margallo, F.M. (2020). Validation of the online theoretical module of a minimally invasive surgery blended learning course for nurses: A quantitative research study. Nurse Education Today, 89, 104406. DOI: 10.1016/j.nedt.2020.104406.

Papageorgiou, K.G. (2020a). Online Coach Development Components: the Tennis Distal Method Coach Development. Pedagogy, $92(7 \mathrm{~s}), 17-28$.

Papageorgiou, K.G. (2020b). On Sports Biomechanics Methodology. Epistēmēs Metron Logos, (4), 50-61. DOI: 10.12681/eml.24289.

Rizzolatti, G., Fadiga, L., Gallese, V., Fogassi, L. (1996). Premotor cortex and the recognition of motor actions. Brain Research. Cognitive Brain Research, 3 (2), 131-141.

Sabock, R. (1981). Professional preparation for coaching. Journal of Physical Education, Recreation and Dance, 52 (8), 10.

Schweitzer, C. (1989). Coaching Certification. ERIC Digest. Retrieved from: www.eric.ed.gov.

Terrace, H.S. (2001). Chunking \& Serially Organized Behavior in Pigeons, Monkeys and Humans. Retrieved from: http://www.pigeon. psy.tufts.edu/avc/terrace (4.09.2013).

Zheng, B., Lin, C.H., Kwon, J.B. (2020). The impact of learner-, instructor-, and course-level factors on online learning. Computers and Education, 150, 103851. DOI: 10.1016/j.compedu.2020.103851.

Cite this article as: Papageorgiou, K.G. (2020). Online Coach Development and Certification Programs in Sports: Are They Possible? Central European Journal of Sport Sciences and Medicine, 4 (32), 69-75. DOI: 10.18276/cej.2020.4-07. 